\title{
STUDY OF SPECTROPHOTOMETRIC CHARACTERISTICS OF THE CHARGE TRANSFER COMPLEX OF TAURINE DRUG WITH 7,7,8,8-TETRACYANOQUINODIMETHANE
}

\author{
Fang Tian a and Sheng Yun $\mathrm{Li}^{\mathrm{a}, *, \text { (D) }}$ \\ a'Department of Chemistry, Taiyuan Normal University, 030619, Jinzhong, Shanxi, China
}

Recebido em 18/08/2019; aceito em 30/09/2019; publicado na web em 15/09/2020

\begin{abstract}
A new spectrophotometric method was developed for the determination of taurine using 7,7,8,8-tetracyanoquinodimethane (TCNQ). The method was based on the formation of charge transfer (CT) complex of this drug as $n$-electron donor with the $\pi$-acceptor TCNQ. TCNQ was found to react with taurine to produce a kind of yellow complex. The spectrum obtained for taurine/TCNQ system showed the maximum absorption band at a wavelength of $420 \mathrm{~nm}$. The formation of such complex was also confirmed by both infrared and ${ }^{1} \mathrm{H}$ NMR measurements. Different variables affecting the reaction were studies and optimized. Beer's law was obeyed in a concentration limit of $1 \sim 9 \mu \mathrm{g} \mathrm{mL}^{-1}$ for taurine. R.S.D. was less than $1.5 \%$, and average recovery was over $100.3 \%$. The stoichiometry of the complex was found to be 1:1 ratio by Job's and straight line methods between the donor and the acceptor. The thermodynamic standard reaction quantities of the complex between the donor and the acceptor were estimated. The developed method could be applied successfully for the determination of the studied compound in the pharmaceutical dosage form with a good precision and accuracy compared to official and reported method as revealed by $t$ - and $F$-tests.
\end{abstract}

Keywords: taurine; 7,7,8,8-tetracyanoquinodimethane (TCNQ); charge transfer (CT) complex; spectrophotometry.

\section{INTRODUCTION}

Taurine (2-amino ethanesulfonic acid) is a sulfur-containing amino acid which is widely used as drug for safeguarding cells. ${ }^{1,2}$ Taurine has biological roles, as a neurotransmitter, detoxification, antioxidation, membrane stabilization, osmoregulation, modulator of intracellular calcium levels and the regulation of protein phosphorylation, and possesses pharmacological properties, being able to protect the liver and benefit the gallbladder, lowers blood pressure and increases anti-arrhythmia. ${ }^{3,4}$ Changes of taurine levels in physiological fluids and tissues also have a close relationship with many illnesses such as Alzheimer's disease, cardiovascular diseases, cancer, epilepsy, retinal degeneration, growth retardation and diabetes mellitus. ${ }^{5}$ It is very important to find a simple and sensitive method to determine content of taurine in clinical medicine.

Several methods have been reported for the determination of taurine, such as HPLC, ${ }^{6} \mathrm{HPTLC}^{7}{ }^{7} \mathrm{MEKC},{ }^{8}$ capillary electrophoresis, ${ }^{9}$ LC-MS/MS, ${ }^{10}$ spectrofluorimetric, ${ }^{11}$ and titrimetric $^{12}$ methods. Several disadvantages can be cited about these methods: complicated expensive equipment, provision for use and disposal of solvents, labor-intensive sample preparation procedure, and personnel skilled (chromatographic techniques and capillary electrophoresis) and laborious, less sensitive, time consuming and only suitable for determining taurine of high content (the titrimetric method) or with low sensitivity and a chemical derivative chromogenic reagent required (spectrofluorimetric). Several spectrophotometric methods have been reported for the determination of taurine. ${ }^{13-16}$ The use of 7,7,8,8-Tetracyanoquinodimethane (TCNQ) for charge transfer (CT) spectrophotometric determination of taurine has not been reported yet. Therefore in this work the application of TCNQ was investigated to find a sensitive method to determine the content of taurine. It was shown that, in slightly alkaline medium, taurine can directly react with TCNQ through CT reaction to form a yellow product. The new, simple, cheap and accurate spectrophotometric method for determination of taurine drug has been developed and validated.

\section{EXPERIMENTAL}

\section{Apparatus}

A Cary300 UV-Vis spectrophotometer provided with matched $10 \mathrm{~mm}$ path-length quartz cells (Varian, USA) was used for absorbance measurements. An infrared spectrometer Nicolet iS5 FT-IR (Thermo Scientific, USA) was used to record the infrared (IR) spectrum. All ${ }^{1} \mathrm{H}$ NMR experiments were carried out on a Bruker Avance III $600 \mathrm{MHz}$ spectrometer (Bruker, Germany). The $\mathrm{pH}$ of the solutions was measured on a 210 precise acidometer (Hanna, Italy).

\section{Reagents}

TCNQ (Sigma Chemical Co., USA) was prepared as $4.9 \times 10^{-3} \mathrm{~mol} \mathrm{~L}^{-1}$ in acetone. The solution was found be stable for at least 1 week at $4^{\circ} \mathrm{C}$.

$0.1 \mathrm{~mol} \mathrm{~L}^{-1}$ of borax buffer solution was prepared.

The standard drug sample of taurine was kindly provided by Chinese National Institute for the Control of Pharmaceutical and Biological Products. Stock standard solution of $8 \times 10^{-3} \mathrm{~mol} \mathrm{~L}^{-1}$ was prepared by dissolving studied standard drug sample in water. Working standard solution of $8 \times 10^{-4} \mathrm{~mol} \mathrm{~L}^{-1}$ was prepared by diluting accurately stock standard solution with water.

All chemicals and solvents used were of analytical reagent grade and purified water.

\section{Pharmaceutical formulation}

The following available commercial preparations were 
analyzed: taurine capsules (Hasen Pharmaceutical Co. Ltd., Shangqiu, China), labeled to contain $250 \mathrm{mg}$ taurine per capsule.

\section{Procedure}

\section{General procedure}

Aliquot of taurine solution was pipetted into a $10 \mathrm{~mL}$ volumetric flask to give final concentrations of $1-9 \mu \mathrm{g} \mathrm{mL}^{-1}$, then $2.0 \mathrm{~mL}$ of TCNQ solution and $0.2 \mathrm{~mL}$ of borax buffer solution were added, and the solution was diluted to volume with purified water and mixed thoroughly. The solution was thermostated at $60{ }^{\circ} \mathrm{C}$ of water bath for $20 \mathrm{~min}$. After rapidly cooling, the absorbency of CT complex of taurine with TCNQ was measured at $420 \mathrm{~nm}$ against a blank solution. The calibration graph was constructed in the same way with working standard solution of known concentration. The amount of studied drug was computed from corresponding calibration graph.

\section{Analysis of pharmaceutical formulation}

The content of 5 capsules of taurine (weighed accurately) was pulverized carefully. An amount of the powdered equivalent to the average weight of the capsule was weighed accurately and transferred into a $250 \mathrm{~mL}$ calibrated flask, dissolved in water, the solution was diluted to volume with water. Working solution was prepared by diluting accurately the solution with water. Then the same detection as mentioned in the section General Procedure was used.

\section{Preparation of the complex for IR measurement}

$10 \mathrm{~mL}$ of $2 \mathrm{mmol} \mathrm{L}^{-1}$ of the drug in water, as well as $10 \mathrm{~mL}$ of $2 \mathrm{mmol} \mathrm{L}^{-1}$ of TCNQ in acetone, was added to a round bottom flask and thermostated at $60^{\circ} \mathrm{C}$ in water bath for $20 \mathrm{~min}$. The solvent was evaporated under reduced pressure and the resulting residues were dried over calcium chloride for IR measurement.

\section{Solution for ${ }^{1} H$ NMR measurements}

$10 \mathrm{mg}$ of taurine was accurately weighed and dissolved in $1 \mathrm{~mL}$ of $d_{6}$-DMSO, and $1 \mathrm{~mL}$ of solution containing an equimolar amount of TCNQ in the same solvent was added. The solution was thermostated at $60{ }^{\circ} \mathrm{C}$ of water bath for $20 \mathrm{~min}$ and subjected directly to ${ }^{1} \mathrm{H}$ NMR measurement.

\section{RESULTS AND DISCUSSION}

\section{Absorption spectra}

The absorption spectra of the complexation product between TCNQ and studied drug are shown in Figure 1. The spectrum obtained for taurine/TCNQ shows a new maximum absorption band at wavelength of $420 \mathrm{~nm}$, which is not due to the absorption of any of the reactant and considered to be a result of CT complex formation between the investigated drug and TCNQ. The new, low energy absorption observed in solution containing both a donor and an acceptor has been described by Mulliken R.S. ${ }^{17}$ as charge transfer transition involving the excitation of an electron on the donor to an empty orbital on the acceptor. Consequently, all subsequent studies were carried out at the absorption maximum against the blank sample. Investigations were carried out to establish the most favorable conditions for the charge

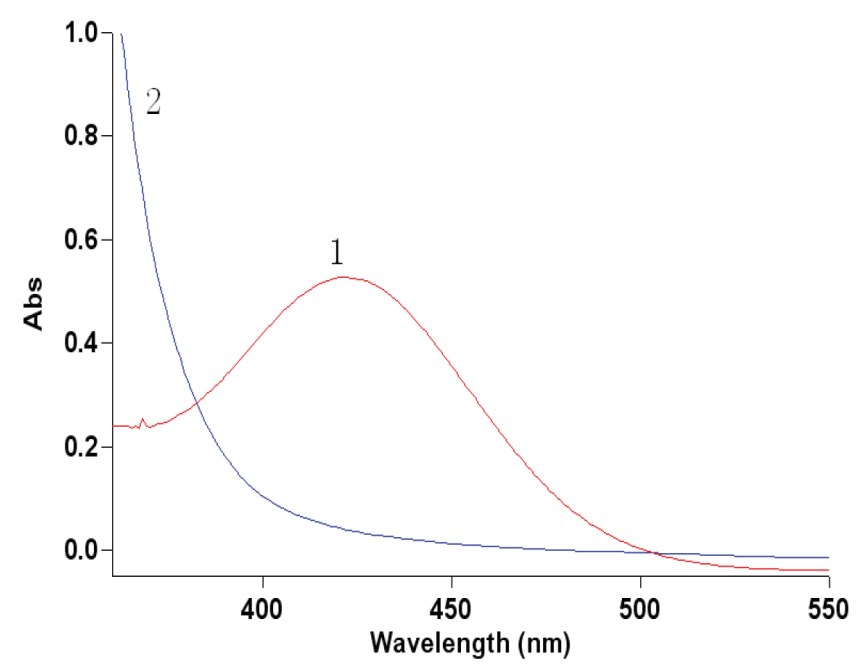

Figure 1. Absorption spectra of the complex 1, Taurine/TCNQ; 2, TCNQ

transfer formation. The influence of some variables on the complexation has been tested as follows.

\section{Effect of solvent}

Absorption spectral characteristics of the CT complex of studied drug with TCNQ in different solvents were compared. The studied solvents involved water, methanol, ethanol, acetone, acetonitrile and dimethylsulphoxide. Experimental results indicated that a mixed solvent of water-acetone gave the maximum and stable absorbance for studied drug, the ratio of water: acetone is $4: 1(\mathrm{v} / \mathrm{v})$.

\section{Effect of reaction temperature and time}

The effect of temperature on the formed CT complex was studied in the range of $20-80^{\circ} \mathrm{C}$. The suitable temperature and time for obtaining maximum and stable absorbance were carried out at $60^{\circ} \mathrm{C}$ and $20 \mathrm{~min}$. The stable time of CT complex at room temperature is at least $2 \mathrm{~h}$.

\section{Effect of pH of working solution}

The absorption spectra of the color product-CT complex in working solution of varying $\mathrm{pH}$ values were recorded in order to select the optimum $\mathrm{pH}$. At $\mathrm{pH}<7.0$ no reaction was observed, due to the low nucleophilicity of the protonated amino-group. At the $\mathrm{pH}$ range of 8.5 to 9.5 , the absorption of the complex was most intensive in borax buffer solution. The suitable volume of borax buffer solution of $0.1 \mathrm{~mol} \mathrm{~L}^{-1}$ was $0.2 \mathrm{~mL}$.

\section{Effect of TCNQ concentration}

The influence of CT reagent concentration was studied in the range 50-400 $\mu \mathrm{g} \mathrm{mL} \mathrm{m}^{-1}$. Experiment indicated that $200 \mu \mathrm{g}$ $\mathrm{mL}^{-1}$ of TCNQ concentration is enough for the compound.

\section{Investigations on the structure of the CT complex}

TCNQ is an $\pi$-acceptor, can formed $n-\pi$ or $\pi-\pi$ CT complex have been reported for determination of many compounds. ${ }^{18}$ The studied drug, an amino acid derivative, may form $n-\pi$ CT complex with TCNQ at the same time. ${ }^{19}$ This interaction takes place, probably, via the nitrogen lone pair in 
the amino ( $n$-electron donor) to TCNQ ( $\pi$-electron acceptor). So, CT complex can be formed with the drug. When TCNQ was added to the studied drug solution, the drug solution with TCNQ causes an immediate change in the absorption spectrum with new characteristic band at $420 \mathrm{~nm}$. The appearance of the new band in the visible region of the spectrum was the evidence for the possible CT complex formation of the type $n-\pi$ CT complex between the studied component and TCNQ.

The formation of the complex was also confirmed by IR measurement. The majority of infrared measurement on the CT complex has been concerned with the shifts in the vibrational frequencies of donor or acceptor. Decrease in the vibration frequency of a particular band has been used as an evidence for a particular site of a CT interaction. ${ }^{20}$ The IR spectra of TCNQ show strong bands at 2221, 1540, and $860 \mathrm{~cm}^{-1}$ corresponding to $\mathrm{v}_{\mathrm{C} \equiv \mathrm{N}}$, aromatic $\mathrm{v}_{\mathrm{C}=\mathrm{C}}$ and 1,4-disubstituted benzene stretching. These bands were shifted in the spectra of the complex with the investigated compound to 2194, 1528, and $848 \mathrm{~cm}^{-1}$, respectively.

In ${ }^{1} \mathrm{H}$ NMR, generally, the protons of the donor are shifted to a lower field (paramagnetic shift). ${ }^{21,22}$ Comparison between the chemical shifts in the ${ }^{1} \mathrm{H}$ NMR spectra before and after reaction helped in ascertaining the exact association of the studied drug. The ${ }^{1} \mathrm{H}$ NMR spectrum of the complex of the investigated compound with the acceptor was measured in $d_{6}$-DMSO together with the spectrum of the free compound. Experimental results indicated that in the ${ }^{1} \mathrm{H}$ NMR spectrum of the complexed taurine, since only the chemical shift of $-\mathrm{CH}_{2}$ in taurine was shifted to a lower field $(\Delta \delta=0.15)$, other protons of the complex showed no evident changes. This could be explained as follows: the unpaired electron on the nitrogen atom of the amino-group of taurine transferred to TCNQ, which induced a decrease of electron cloud density on the proton of $-\mathrm{CH}_{2}$ of taurine, as a result, a lower field chemical shift occurred. This indicated that the complexation binding of TCNQ with the nitrogen atom of the amino-group of taurine gave rise to the CT complex.

Stoichiometry of the complex was determined by Job's method of continuous variations, in which master solutions of equimolar concentrations of the donor and acceptor were used in this experiment, and it was found to be 1:1 for the drug with TCNQ. Further support has been observed in the straight line method which can be used as a qualitative mean for the determination of the stoichiometry ratio of the donor and acceptor in the complex. This ratio is likely to engender owing to the presence of the nitrogen atom acting as an electron drawing group in the molecule of studied drug. The nitrogen atom in amino has more electron density and less sterically hindered. So, $n-\pi$ CT complex was formed (Figure 2).

The association constant for the interaction of studied compound with TCNQ was estimated according the BenesiHildebrand Equation when the concentration of acceptor is excess enough to regard $\left[\mathrm{A}_{0}\right] \geq\left[\mathrm{D}_{0}\right]$ : $^{23}$

$$
\frac{\left[\mathrm{A}_{0}\right]}{A^{\mathrm{AD}}}=\frac{1}{\varepsilon^{\mathrm{AD}}}+\frac{1}{K_{\mathrm{CT}} \varepsilon^{\mathrm{AD}}} \times \frac{1}{\left[\mathrm{D}_{0}\right]}
$$

where $\left[\mathrm{A}_{0}\right]$ and $\left[\mathrm{D}_{0}\right]$ are the total concentrations of the acceptor and donor, respectively, $A^{\mathrm{AD}}$ is the absorbance of the complex at the $\lambda_{\max }, \varepsilon^{\mathrm{AD}}$ is the molar absorptivity of the complex, and $K_{\mathrm{CT}}$ is the association constant of the complex . From the previous equation, on plotting the values of $\left[\mathrm{A}_{0}\right] / A^{\mathrm{AD}}$ versus $1 /\left[\mathrm{D}_{0}\right]$, straight line was obtained (Figure 3), from which the

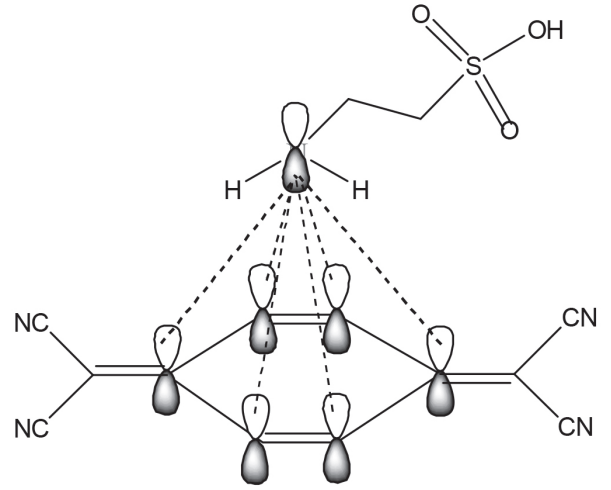

Figure 2. The structural formula of CT complex produced from taurine with $T C N Q$

association constant and correlation coefficient were obtained (Table 1).

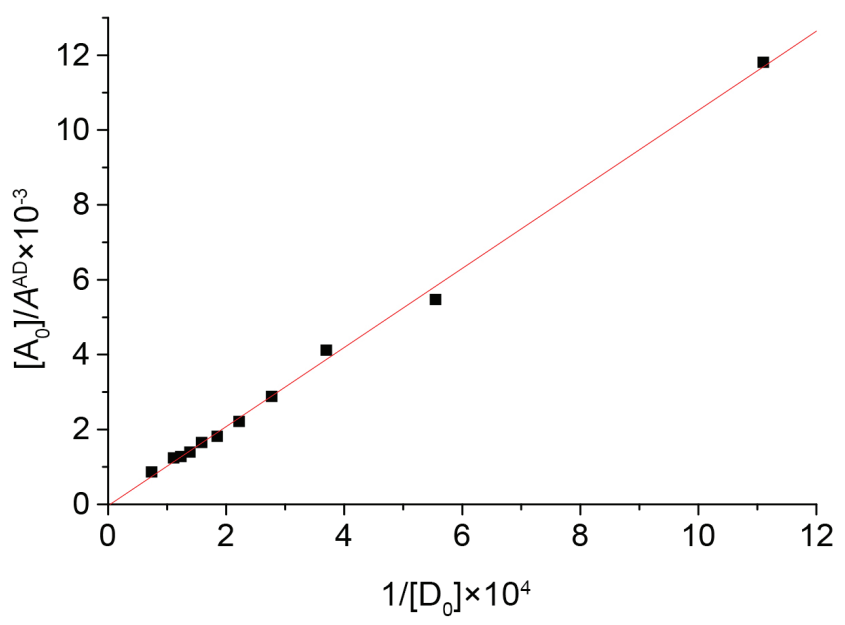

Figure 3. The curve of $\left[A_{0}\right] / A^{A D}$ versus $1 /\left[D_{0}\right]$ in TCNQ-Taurine system

Table 1. The association constant of the complex between donor and acceptor

\begin{tabular}{lc}
\hline Parameters & Taurine-TCNQ \\
\hline$\lambda(\mathrm{nm})$ & 420 \\
$K_{\mathrm{CT}}$ Association constant $\left(\mathrm{L} \mathrm{mol}^{-1}\right)$ & 334 \\
Correlation coefficient $(r)$ & 0.99879
\end{tabular}

$\Delta G^{\circ}$ value of the complex is calculated from Gibbs free energy of formation according to the relationship:

$$
\Delta G^{\circ}=-2.303 R T \log K_{C T}
$$

where $\Delta G^{\circ}$ is the free energy of the CT complex, $R$ the gas constant $\left(8.314 \mathrm{~J} \mathrm{~mol}^{-1} \mathrm{~K}^{-1}\right), T$ the temperature in Kelvin degrees, and $K_{\mathrm{CT}}$ is the association constant of donor-acceptor complex $\left(\mathrm{L} \mathrm{mol}^{-1}\right)$.

$$
\Delta G^{\circ}=-R T \ln K_{C T}=\Delta H^{\circ}-T \Delta S^{\circ}
$$

The thermodynamic standard reaction quantities $\left(\Delta H^{\circ}\right.$ and $\Delta S^{\circ}$ ) of the complex between donor and acceptor were estimated from the temperature dependence of the association constant by plotting $\ln K_{\mathrm{CT}}$ versus $1 / T$. $^{24}$

For the studied system, there is no evidence for the deviation from the linearity of the plot of $\ln K_{\mathrm{CT}}$ versus $1 / T$ 


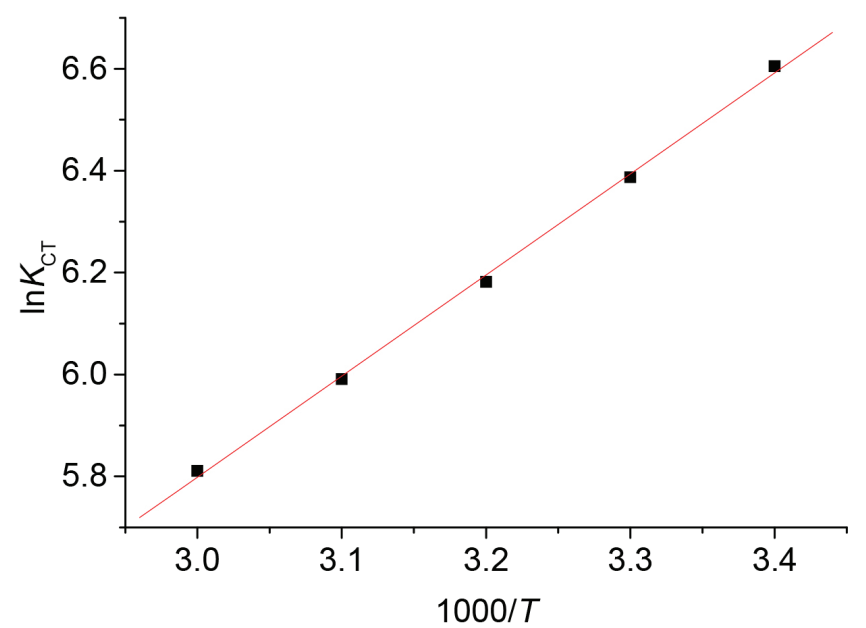

Figure 4. Relation between $\ln K_{C T}$ and $1 / T$ for CT complex of TCNQ-Taurine

over the investigated temperature range (Figure 4).

The parameters thus obtained are represented in Table 2, and these values show that complexation is thermodynamically favored.

Table 2. The thermodynamic constants of the complexes between donors and acceptor

\begin{tabular}{lc}
\hline Parameters & Taurine-TCNQ \\
\hline$\Delta G^{\circ}$ Free energy $\left(\mathrm{kJ} \mathrm{mol}^{-1}\right)$ & -16.1 \\
$\Delta H^{\circ}$ Enthalpy $\left(\mathrm{kJ} \mathrm{mol}^{-1}\right)$ & -17.6 \\
$\Delta S^{\mathrm{o}}$ Entropy $\left(\mathrm{J} \mathrm{mol}^{-1} \mathrm{~K}^{-1}\right)$ & -4.8 \\
Correlation coefficient $(r)$ & 0.99927 \\
\hline
\end{tabular}

\section{Analytical parameters}

Under the experimental conditions described, standard calibration curve of the CT complex for the drug was constructed by plotting absorbency intensity versus concentration. The linear regression equation is listed in Table 3 . The correlation coefficient 0.99839 indicated good linearity. The small value of variance confirmed the small degree of scattering of the experimental data points around the regression line.

\section{Analytical application}

The obtained high-absorbance bands and the very low reagent background make this procedure suitable for the routine quality control analysis of the investigated compound with minimum interference. The proposed method and official method $^{12}$ were applied to the determination of studied drug in capsules. Moreover, to check the validity of the proposed
Table 3. Quantitative parameters for the CT complex of studied drug with TCNQ

\begin{tabular}{lc}
\hline Parameters & Taurine-TCNQ \\
\hline$\lambda_{\max }(\mathrm{nm})$ & 420 \\
Beer's law limits $\left(\mu \mathrm{g} \mathrm{mL}^{-1}\right)$ & $1-9$ \\
Limit of detection $\left(\mu \mathrm{g} \mathrm{mL}^{-1}\right)$ & 0.2 \\
Intercept on the ordinate $(a)$ & -0.00328 \\
Slope $(b)$ & 0.08703 \\
Molar absorptivity $(\varepsilon)\left(\mathrm{L} \mathrm{mol}^{-1} \mathrm{~cm}^{-1}\right)$ & $1.09 \times 10^{4}$ \\
Correlation coefficient $(r)$ & 0.99839 \\
Sandell sensitivity $\left.(\mu \mathrm{g} \mathrm{cm})^{-2}\right)$ & 0.011 \\
\hline
\end{tabular}

method, the standard addition method was applied by adding studied pure drug to the previously analyzed capsules. The recovery of the drug was calculated by comparing the concentration obtained from the mixtures with those of the pure drug. Five replicate determinations were made (Table 4), and the obtained mean values \pm S.D. of the labeled amounts ranged from $100.9 \pm 1.21$ to $102.3 \pm 0.68$, the recovery ranged from $99.1 \pm 0.86$ to $101.5 \pm 0.65$. In the $t$ - and $F$-tests, no significant differences were found between the calculated and theoretical values (95\% confidence) of both the proposed and official method, ${ }^{12}$ and this indicated similar precision and accuracy between them.

Precision of the proposed method was determined in each concentration range, by eleven measurements carried out on different days within a week of different solution of studied drug. Target concentrations corresponded to middle values of each range. Table 5 gives an R.S.D. (within-day and betweenday) of solutions of certain concentrations were determined by using the proposed procedure.

The assay result was unaffected by the presence of excipients as shown by the excellent recoveries obtained when analyzing the studied drug in presence of commonly encountered excipients. As samples containing a fixed amount of the studied drug $\left(5 \mu \mathrm{g} \mathrm{mL}^{-1}\right)$ and excipients $\left(50 \mu \mathrm{g} \mathrm{mL} \mathrm{L}^{-1}\right)$ were measured, no interference was observed from commonly used excipients such as starch, lactose, glucose, fructose, sucrose, and magnesium stearare. This fact indicates good selectivity of the method to determine the studied drug both in raw material and in their dosage forms.

\section{CONCLUSIONS}

The main results obtained from the present study indicate that the $n-\pi$ CT complex's formation between taurine and TCNQ was authenticated, and the different variables affecting

Table 4. Determination of the drug in pharmaceutical formulation using TCNQ $(n=5)$

\begin{tabular}{|c|c|c|c|}
\hline \multirow[b]{2}{*}{ Drug } & \multicolumn{2}{|c|}{ Present method } & \multirow{2}{*}{$\begin{array}{c}\text { Reference method }{ }^{12} \\
\text { Equivalent nominal conten } \\
(\%) \pm \text { S.D. }{ }^{a}\end{array}$} \\
\hline & $\begin{array}{l}\text { Equivalent nominal content } \\
\qquad(\%) \pm \text { S.D. }{ }^{a}\end{array}$ & $\begin{array}{l}\text { Recovery } \\
(\%)\end{array}$ & \\
\hline \multicolumn{4}{|l|}{ Taurine } \\
\hline Pure drug & $100.9 \pm 1.21(t, 1.14 ; F, 3.36)$ & & $100.2 \pm 0.66$ \\
\hline capsule (250 mg) (I) & $102.3 \pm 0.68(t, 1.97 ; F, 2.75)$ & $99.1 \pm 0.86$ & $102.5 \pm 0.41$ \\
\hline Capsule (250 mg) (II) & $101.6 \pm 1.11(t, 0.74 ; F, 5.35)$ & $101.5 \pm 0.65$ & $101.2 \pm 0.48$ \\
\hline
\end{tabular}

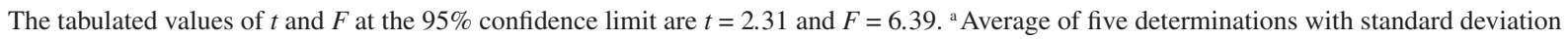


Table 5. Precision results of the proposed methods $(n=11)$

\begin{tabular}{lccc}
\hline Drug & $\begin{array}{c}\text { Concentration } \\
\left(\mu \mathrm{g} \mathrm{mL}^{-1}\right)\end{array}$ & $\begin{array}{c}\text { Within-day } \\
\text { R.S.D. }\end{array}$ & $\begin{array}{c}\text { Between-day } \\
\text { R.S.D. }{ }^{\mathrm{a}}(\%)\end{array}$ \\
\hline Taurine & 2 & 1.5 & 0.8 \\
& 5 & 0.7 & 1.0 \\
& 8 & 0.7 & 0.9 \\
\hline
\end{tabular}

average of eleven determinations.

the CT complexation were optimized. The developed method was applied successfully to the spectrophotometric assay of taurine in its dosage forms without fear of interference caused by the excipients to be present in its dosage forms. The present method for the determination of taurine drug has the advantages of easy operation, high recovery, less timeexpense, and less use of organic solvent. The investigation of real samples revealed the potential of the method in pharmaceutical analysis.

\section{SUPPEMENTARY MATERIAL}

Supplementary data are available on http://quimicanova. sbq.org.br in the form of a PDF file, with free access.

\section{ACKNOWLEDGEMENTS}

This work was financial supported by the National Natural Science Foundation of China (No. 20776004) and Shanxi Natural Science Funding (No. 2014011014-8).

\section{REFERENCES}

1. Jeon, S. H.; Lee, M. Y.; Kim, S. J.; Joe, S. G.; Kim, G. B.; Kim, I. S.; Kim, N. S.; Hong, C. U.; Kim, S. Z.; Kim, J. S.; Kang, H. S.; FEBS Lett. 2007, 581, 5929.

2. Che, Y.; Hou, L.; Sun, F.; Liu, X.; Piao, F.; Zhang, D.; Li, H.; Wang, Q.; Cell Death Dis. 2018, 9, 468.

3. Huxtable, R. J.; Physiol. Rev. 1992, 72, 101.

4. Bucolo, C.; Fidilio, A.; Platania, C. B. M.; Geraci, F.; Lazzara, F.; Drago, F.; J. Ocul. Pharmacol. Th. 2018, 34, 188.

5. Zinellu, A.; Sotgia, S.; Bastianina, S.; Chessa, R.; Gaspa, L.; Franconi, F.; Deiana, L.; Carru, C.; Amino Acids 2009, 36, 35.

6. Chen, X. M.; You, J.M.; Suo, Y. R.; Fan, B. L.; J. CHROMATOGR. SCI. 2015, 43, 492 .

7. Magesh, A. R.; Dhanaraju, M. D.; American Journal of Analytical Chemistry 2017, 8, 742 .

8. Vochyánová, B.; Opekar, F.; T ma, P.; ELECTROPHORESIS 2014, 35, 1660.

9. Du, F.; Zhao, W.; Cao, S.; Fung, Y. S.; J. Sep. Sci. 2015, 38, 3271.

10. Tang, D. Q.; Bian, T. T.; Zheng, X. X.; Li, Y.; Wu, X. W.; Li, Y. J.; Du, Q.; Jiang, S. S.; Biomed. Chromatogr. 2014, 28, 1173.

11. Sharaf El Din M. K.; Wahba M. E. K.; Luminescence 2015, 30, 137.

12. The State Pharmacopoeia Commission, Pharmacopoeia of People's Republic of China, China Pharmaceutical Science and Technology Press: Beijing, 2015, 2, p. 77.

13. Portnaya, E. P.; Vasyuk, S. A.; Pharm. Chem. J. 2014, 48, 553

14. Lau, O. W.; Luk, S. F.; Chiu, T. P. Y.; Analyst 1990, 115, 653.

15. Mohamed, M. K. S.; Elbashir, A. A.; Enein, H. Y. A.; Curr. Pharm. Anal. 2017, 13, 11.

16. Omer, M. M. A.; Omar, M. M. A.; Abdelaziz, M. A.; Thiel, A.; Elbashir, A. A.; J Food Chem Nanotechnol 2019, 5, 1.

17. Mulliken, R. S.; J. Chem. Phys. 1939, 7, 20.

18. Du, L. M.; Yang, Y. Q.; Wang, Q. M.; Anal. Chim. Acta. 2004, 516, 237.

19. Li, S. Y.; Hou, Y. C.; Bull. Chem. Soc. Ethiop. 2014, 28, 187.

20. Foster, R.; Organic Charge-Transfer Complexes, Academic Press: London, 1969, pp. 51, 387.

21. Saleh, G. A.; Talanta 1998, 46, 111

22. Li, W. Y.; Chen, X. F.; Xuan, C. S.; Spectrochim Acta A 2009, 71, 1769.

23. Benesi, H. A.; Hidelbrand, J.; J. Am. Chem. Soc. 1949, 71, 2703.

24. Person, W. B.; J. Am. Chem. Soc. 1962, 84, 536. 